\begin{tabular}{|c|c|c|}
\hline 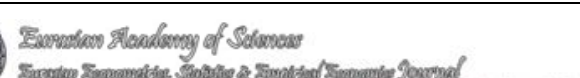 & $\begin{array}{r}\text { Eurasian Academy of } \\
\text { Eurasian Econometrics, Statistics \& Em }\end{array}$ & nics Journal \\
\hline 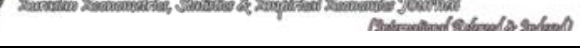 & Volume:1 & S: $18-31$ \\
\hline \multicolumn{3}{|c|}{$\begin{array}{l}\text { Published Online April } 2015 \text { (http://econstat.eurasianacademy.org) } \\
\text { http://dx.doi.org/10.17740/eas.stat.2015-V1-02 }\end{array}$} \\
\hline
\end{tabular}

\title{
Analysis of Foreign Debt and Economic Growth in Turkey by Using Core Regression
}

Hasan Alp Özel *

* Karabük Üniversitesi

E-mail: alpalp78@hotmail.com

Received : 31 March 2015; Published : 30 November -0001

Copyright (C) 2015 Hasan Alp Özel. This is an open access article distributed under the Eurasian Academy of Sciences License, which permits unrestricted use, distribution, and reproduction in any medium, provided the original work is properly cited.

\begin{abstract}
The duration and volume of foreign indebting bear an important issue for every economy no matter how developed it is. Foreign indebting, which is applied when domestic savings can not meet the planned investments, causes different results based on the economic structures and the way that they use these funds. This study investigates the relationship between foreign debt and economic growth for Turkish economy using core regression method. The data have been obtained from the statistics database of World Bank for the years 1970 to 2013 annually. Existing data reveals that 1 unit increase in foreign debt of Turkey decreases economic growth at about 0,12
\end{abstract}

Keywords: Economic Growth, Foreign Debt, Turkish Economy, Core Regression, Sustainable Indebting.

JEL: O10, O16,O47,F34,H63

\section{Türkiye'de Dış Borç ve Ekonomik Büyüme İlişsisinin Çekirdek Regresyon Yardımıyla Analizi}

\section{ÖZET}

Ekonomik gelişmişlik düzeyi ne olursa olsun, ülke ekonomileri için dış borçlanma zamanı ve miktarı önemli bir konuyu oluşturmaktadır. Dış borçlanma, özellikle ıcari acık ya da iç tasarrufların planlanan yatırımları karşılayamaması nedenleriyle başvurulması sonucunda ülkelerin ekonomik yapılarına ve borçların kullanımına göre farkll sonuçlar ortaya koymaktadır. Bu çalışmada Türkiye ekonomisi için dış borç ekonomik büyüme ilişkisi çekirdek Regresyon yöntemi ile araştırılmıştır. Ekonomik veriler Dünya Bankası istatistik verilerinden 1970-2013 yıllık olarak derlenmiştir. Mevcut veriler 1şığında Türkiye'nin dış borcunda meydana gelen 1 birimlik artışın ekonomik büyümeyi 0,12 azalttığı görülmektedir.

Anahtar Kelimeler: Ekonomik Büyüme, Dış Borç, Türkiye Ekonomisi, Ç'ekirdek Regresyon, Sürdürülebilir Borçlanma 


\section{Giriş}

Az gelişmiş ve gelişmekte olan ülkelerdeki tasarruf eksikliği ve düşük ihracat gelirleri, diş borçlanmayı yatırımların finansmanı için alternatif bir seçenek olarak ortaya çıkarmıştır. Merkez bankası, tüm kamu kurum ve kuruluşları ile özel sektörün yurtdışı yerleşiklerden sağlamış oldukları krediler ve yurtdışı piyasalarda ihraç ettikleri tahvillerden doğan yükümlülükler toplam diş borç stokunu oluşturmaktadır (Susam ve Bakkal, 2008). Ülkelerin ekonomik kaynak bulma ihtiyacının temelinde karşılaştıkları yatırım-tasarruf açı̆̆ı bulunmaktadır (Akçay, 2012). Ayrıca iç borçlanmanın yeterli olmayışı, gerekli ithalat için yeterli döviz bulunamaması, ödemeler dengesi açıkları gibi nedenlerle de ülkeler dış borçlanmaya gidebilmektedir (Bilginoğlu ve Aysu 2008). Mal ve hizmet ticareti ile transfer ödemelerinde meydana gelen açığın kapatılması için de dış borçlanmaya başvurulmaktadır (Çukurçayır, 2014). Tasarruf ve tasarruflara bağlı olarak da yatırım eksikliği ekonominin genelinde olabileceği gibi sadece özel sektörde ya da kamu sektöründe olabilir. Dolayısıyla dış borçlanma sermaye piyasasının serbestlik düzeyine bağlı olarak hem kamu sektörü hem de özel sektör tarafından yapılabilmektedir (Çevik ve Cural, 2013).

\section{Dış Borçlanma ve Ekonomik Büyüme İlişsisinin Teorik Temelleri}

Dış borçlanma devletin ekonomik faaliyetlere mümkün olduğunca karışmaması gerektiğini savunan klasik iktisadi düşüncenin terk edilip, ekonomik büyümenin canlanması için devlet müdahalesinin gerekliliğini savunan Keynesyen iktisadi düşüncenin popülerlik kazanmasıyla önem kazanmıştır (Çöğürcü ve Çoban, 2011). Temelde dış borçlanmanın verimli yatırım harcamalarında kullanılması, uzun vadeye yayılarak düşük faizli olması ekonomik büyümeyi olumlu etkileyen bir faktör olarak karşımıza çıkmaktadır. Ancak dış borçlanmanın faizi yüksek ise ve dış borçlanma ile yapılan yatırımlar geri ödeme düzeyini sağlayabilecek gelirden daha düşük ise ekonomik büyümeyi olumsuz etkilemektedir (Bilginoğlu ve Aysu, 2008).Yabancı kaynak girişi başlangıç aşamasında ekonomilerde olumlu etki yaratsa da, borçların ödenme dönemlerinde ülke dışına kaynak transferine yol açmaktadır. Alınan dış borçların etkin ve verimli bir şekilde kullanılmayışı giderek artan borcun borç ile ödenme kısır döngüsüne girilmesine neden olmaktadır (Ersoy, 2013).

Dış borç-ekonomik büyüme ilişkisinin temel çerçevesini oluşturan teorileri zamanlar arası borçlanma modeli, borçla büyüme modeli, borç fazlası modeli ve sürdürülebilirlik yaklaşımı modeli oluşturmaktadır.

Zamanlar arası borçlanma modeli dış borcun ülkedeki tasarruf açığını kapatmadaki önemini vurgulamak üzere oluşturulan bir modeldir (Erataş ve Başc1, 2013). Model iki dönem için bir ülkenin zamanlar arası fayda maksimizasyonunu üzerine kurulmuştur. Modelde, bir ülkenin uluslararası sermaye piyasalarına hiç erişimi olmadığ 1 ve hem üreticilerin hem de tüketicilerin dünya faiz oranından fazla olan yurtiçi faiz oranı ile karşı karşıya oldukları otarşi durumunu göstermektedir. Uluslararası borçlanmaya açılma ile birlikte ülke daha düşük faiz oranına tepki gösterir ve daha yüksek cari tüketme sahip olur (Nissanke ve Ferrarini, 2001).

Borçla büyüme modeli, tasarruf eksikliği nedeniyle üstlenilemeyen yatırımların dış borç sağlanarak karşılanmasını temeline dayanmaktadır (Bilginoğlu ve Aysu, 2008). Borçla büyüme modeli, borç kapasitesini ekonomik büyüme sürecinde borçlanmanın fayda ve maliyetleri olarak dikkate alır. Modelin temel dayanağı, zamanla ek borçllanmanın ekonomik büyümeye yeterince katkı sağlaması durumunda bir ülkenin borçları döndürme kapasitesini sürdüreceğidir. Sermaye akışlarının ekonomik büyüme ve kalkınmanın gidişatı ile yakından 
ilişkili olan birkaç aşama süresince değiş̧ebileceği bir borç döngüsü önerilmektedir. Bununla birlikte önerilen borç büyüme sürecinde hiç otomatisite olmadığ 1 için, farklı aşamalarda ilerlemede birkaç koşulun karşılanmasını gerektirir. Genellikle bu koşullar Harrod-Domar büyüme modeli çerçevesinde tek bir koşul olarak birleşmektedir. Koşul zaman içerisinde borç servisi kapasitesini sürdürmek, bir başka deyişle borcunu ödeyebilecek durumda kalmak için, çıktı büyüme oranının, faiz oranı olarak ölçülen borçlanma maliyetine eşit veya fazla olması gerektiğini belirtmektedir (Hjertholm, 20007). Borçla büyüme modeline göre, ülkeye giren yabancı kaynaklar sermaye malı ithalatının oluşturduğu cari işlemler açığını finanse ederse ve ülkedeki yatırım hızında bir artış meydana gelirse, ekonominin daha hızlı büyümesi gündeme gelmektedir (Bilginoğlu ve Aysu, 2008).

Borç fazlası modeli, borcun ülkenin gelecekte belli bir olasılıkla geri ödeme kabiliyetini geçmesi halinde, beklenen borç servisinin muhtemelen ülkenin çıktı seviyesinin artan bir fonksiyonu olacağı önermesine dayanmaktadır. Böylece yerel ekonomiye yapılan yatırımdan elde edilen getirilerin bir kısmı mevcut yabancı alacaklılar tarafından etkin bir şekilde alınır, yurtiçi ve yeni yabancı yatırımcılar tarafından yapılacak yatırımlar caydırılır. Geleceğe yönelik borç yükümlülüklerinde meydana gelecek bir indirim ise yatırımları arttırıcı etki yapacaktır. Borcun azalması yatırımın ve geri ödeme kapasitesinin artmasına yol açtığı için, dolaşımdaki borç daha yüksek olasılıkla geri ödenecek duruma gelmektedir. Bu etki yeterince güçlü ise, borcun azalması borçluya olduğu kadar alacaklılara da faydalı olabilir. Dış borçlanma, yatırımlar açısından ek bir kaynak sağlamasından dolayı ekonomik büyümeyi olumlu etkilemektedir. Ancak dış borçların varlığı ödeme dönemlerinde dışarıya kaynak çıkışı yarattığı için ekonomik büyümeyi olumsuz etkilemektedir. Ĕger borç gelecekte ülkenin ödeyebileceğinden daha fazla ise beklenen borç servisi maliyetleri gelecekteki yerli ve yabancı yatırımları caydırmaktadır. Çünkü ülkenin fazla üretimi dış borç servisini karşılamak üzere daha yüksek oranda vergilendirilmektedir. Bu durum Borç Laffer Eğrisi ile gösterilmektedir (Bilginoğlu ve Aysu, 2008). Borçlu, Laffer eğrisinin sağ tarafinda olursa, borç azalması beklenen borç geri ödemesini arttırıcı etki yapar (Claessens vd. 1997; Pattillo vd. 2002; Diego vd. 2009). Krugman (1988 a) ve Foot (1989), yüksek borç stoku seviyesinin azaltılması ile beklenen borç geri ödemesinin arttırılabileceğini savunmaktadır (Husain, 1997). Olası gelecekteki kaynak transferinin beklenen şimdiki değeri borçtan az olduğunda, bir ülkenin borç fazlası sorununa sahip olduğu söylenebilir (Krugman, 1988 b). Borç fazlası teorisi, borç akışını yeniden planlamak yerine borç düşürmeyi destekleyen bir teoridir.

Sürdürülebilirlik yaklaşımına göre, dış borçların sürdürülebilirliği borçlanmadan elde edilen kaynaklarla, gelirlerin gelecekteki borç servisini karşılayabilecek şekilde arttırılması ile olanaklıdır. Mali dengesizlik durumunda, belli bir maliyete katlanarak ek kaynaklar sağlanmaya çalışılmaktadır. Bu maliyet fon arz ve talebince belirlenen faiz oranıdır. Borç alma sürecinin sürdürülebilirliği, borç olarak alınan kaynakların etkin bir şekilde kullanılmasıyla mümkündür. Ancak bu şekilde borç servisi yeni borçlanmaya başvurmaksızın karşılanabilmektedir (Ülgen, 2002). D1ş borçlanma ile elde edilen kaynak yabancı borçlanmanın maliyetinden fazla bir getiri ürettikçe, bir ülke yurt dışından borçlanmalıdır. $\mathrm{Bu}$ durumda borçlanan ülke yabancı tasarruflar yardımıyla üretim kapasitesini arttırmaktadır. Teorik olarak dış borçlanmanın sürdürülebilir seviyesini şartlara, vade ve yabancı sermayenin mevcudiyetine bağlı olarak hesaplamak mümkündür. Bununla birlikte uygulamada bu bilgilere ulaşmak kolay olmamaktadır. Dolayısıyla borcun ihracata oranı, borç servisinin ihracata oranı, borcun gayri safi yurtiçi hasıla veya gayri safi milli hasılaya oranı gibi çeşitli oranlar sürdürülebilirliğin standart ölçüleri olmuşlardır. Bu tür oranların sürdürülebilir seviyesini belirlemek güç olmasına rağmen, bu oranların pratik değeri yabancı borç stokunda 
potansiyel olarak büyümeye ilişkin uyarı verir. İlave yabancı borçlanma borç servis yükünü, ülkenin o yükü taşıma kapasitesini artırdığından daha fazla artırırsa, ihracat artırılarak durum tersine döndürülmelidir. Aksi durumda ise koşullar değişmez ve ödemeleri yapmak için daha fazla borçlanmaya gereksinim duyulur ve dış borç ülkenin borcu servis etme kapasitesinden daha hızlı büyüyecektir (Ajayi ve Khan, 2000).

\section{Literatür Taraması}

D1ş borçların ekonomik büyüme üzerine etkisi akademik literatürde sıklıkla incelenen bir konudur. Bunun nedeni, dış borçların ülkelerin iç ekonomik dinamiklerine bağlı olarak farklı dönemlerde farklı etkilere sahip olabilmesidir. Teoride tasarruf eksikliğinin dış borç ile telafi edilmesinin ekonomik büyümeyi desteklediği görüşü öne çıksa da, uygulamada dış borçların verimli kullanılamaması, borçlanma yoluyla yapılan yatırımların bekllenen getiriyi elde edememesi sonucunda ekonomileri borcun borçla ödendiği bir kısır döngüye sokarak ekonomiyi bir borç sarmalına sürüklediği ve ekonomik büyümeyi olumsuz etkiledi görüşleri de bulunmaktadır. Böylece daha önceden alınan borçların ödenebilmesi için tekrar borçlanılmak zorunda kalınmaktadır (Ingham, 1995).

Türkiye ekonomisi açısından dış borç ekonomik büyüme ilişkisine yönelik literatür taramasına bakıldığında öne çıkan görüşün dış borçlarda meydana gelen artışın ekonomik büyümeyi olumsuz etkilediği yönünde olduğu görülmektedir. Ülke gruplarına yönelik yapılan çalışmalarda ise belirli bir diş borç stokundan sonra artan dış borçlanmanın ekonomik büyümeyi olumsuz etkilediği görüşü ön plana çıkmaktadır.

\begin{tabular}{|c|c|c|}
\hline Yazar(lar) & $\begin{array}{l}\text { Ülke(ler) ve } \\
\text { Dönem }\end{array}$ & Bulgular \\
\hline \multicolumn{3}{|l|}{$\begin{array}{l}\text { Olumlu etkilere yönelik } \\
\text { çalışmalar }\end{array}$} \\
\hline $\begin{array}{l}\text { Abu Bakar ve Haasan } \\
(2008)\end{array}$ & $\begin{array}{l}\text { Malezya / 1970- } \\
2005\end{array}$ & $\begin{array}{l}\text { D1ş Borçtaki \%1'lik artış, uzun dönemde } \\
\text { ekonomik } \quad \text { büyüımeyi } \% 1,29 \\
\text { arttırmaktadır. }\end{array}$ \\
\hline Patenio ve Tan-Cruz (2007) & $\begin{array}{l}\text { Filipinler / 1981- } \\
2005\end{array}$ & $\begin{array}{l}\text { D1ş borç servisi, ekonomik büyümeyi } \\
\text { çok az etkilemektedir ve borç fazlası } \\
\text { teorisinin gerçekleşeceği kadar yüksek } \\
\text { değildir. }\end{array}$ \\
\hline Schclarek (2004) & $\begin{array}{l}59 \text { GOÜ ve } 24 \\
\text { gelişmiş ülke }\end{array}$ & $\begin{array}{l}\text { Düşük dış borçlanma düzeyi, ekonomik } \\
\text { büyümeyi arttırmaktadır. Dış borç ile } \\
\text { toplam faktör verimliliği arasında sınırlı } \\
\text { bir ilişki vardır. }\end{array}$ \\
\hline $\begin{array}{l}\text { Patillo, Poirson ve Ricci } \\
(2002)\end{array}$ & $\begin{array}{l}93 \text { GOÜ/1969- } \\
1998\end{array}$ & $\begin{array}{l}\text { Düşük düzeyli diş borçlanma ekonomik } \\
\text { büyüme üzerinde olumlu etkiye sahiptir. } \\
\text { Ekonomik büyümeyi maksimize eden } \\
\text { borç/GSYİH oran } \% 20 \text { 'dir. }\end{array}$ \\
\hline \multicolumn{3}{|l|}{$\begin{array}{l}\text { Olumsuz etkilere yönelik } \\
\text { çalışmalar }\end{array}$} \\
\hline Safradi ve Mehziri (2011) & İ́ran /1974-2007 & $\begin{array}{l}\text { Dış borçlar ekonomik büyümeyi ve özel } \\
\text { yatırımları olumsuz etkilemektedir. }\end{array}$ \\
\hline Reinhart ve Rogoff (2010 a) & $\begin{array}{c}44 \text { gelişmiş ve } \\
\text { GOÜ / 1971-2009 }\end{array}$ & $\begin{array}{l}\text { Yüksek diş borç stoku ekonomik } \\
\text { büyümeyi olumsuz etkilerken, bu etki }\end{array}$ \\
\hline
\end{tabular}




\begin{tabular}{|c|c|c|}
\hline & & $\begin{array}{l}\text { gelişmekte olan ülkelerde daha belirgin } \\
\text { olmaktadır. }\end{array}$ \\
\hline Hayat ve Hayat (2010) & $\begin{array}{l}\text { Pakistan / 1972- } \\
2005\end{array}$ & $\begin{array}{lll}\begin{array}{l}\text { Diş borçta } \\
\text { ekonomik }\end{array} & \begin{array}{l}\text { meydana } \\
\text { büyümeyi }\end{array} & \begin{array}{r}\text { gelen artış } \\
\text { olumsuz } \\
\text { etkilemektedir. }\end{array}\end{array}$ \\
\hline Reinhart ve Rogoff (2010 b) & $\begin{array}{l}\text { 64 gelişmiş ve } \\
\text { GOÜ/ 1914-2010 }\end{array}$ & 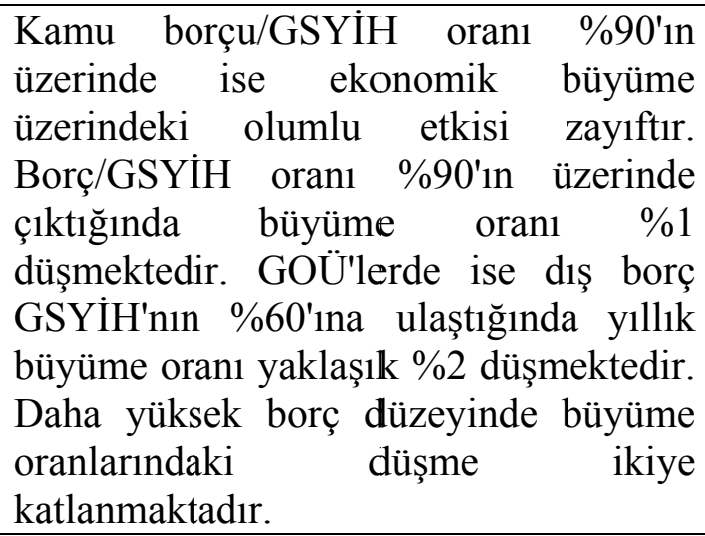 \\
\hline \multicolumn{3}{|l|}{$\begin{array}{l}\begin{array}{l}\text { Türkiye'ye } \\
\text { çalışmalar }\end{array} \\
\end{array}$} \\
\hline Çelik ve Direkçi (2013) & $\begin{array}{l}\text { Türkiye/ 1991- } \\
2010\end{array}$ & $\begin{array}{l}\text { Dış borç ekonomik büyüme üzerinde } \\
\text { negatif bir etkiye sahiptir. }\end{array}$ \\
\hline Çevik ve Çural (2013) & $\begin{array}{l}\text { Türkiye/1989- } \\
2012 \\
\end{array}$ & $\begin{array}{l}\text { D1ş borçlanma ekonomiyi pozitif } \\
\text { etkilemektedir. }\end{array}$ \\
\hline Çöğürcü ve Çoban (2011) & $\begin{array}{l}\text { Türkiye/1980- } \\
2009\end{array}$ & $\begin{array}{l}\text { Diş Borçlanma ekonomik büyüme } \\
\text { üzerinde negatif etkiye sahiptir. }\end{array}$ \\
\hline Uysal vd. (2009) & $\begin{array}{l}\text { Türkiye/ 1965- } \\
2007\end{array}$ & $\begin{array}{l}\text { Dış borç ekonomik büyüme üzerinde } \\
\text { negatif bir etkiye sahiptir. }\end{array}$ \\
\hline Bilginoğlu ve Aysu (2008) & $\begin{array}{l}\text { Türkiye/ 1968- } \\
2005\end{array}$ & $\begin{array}{l}\text { D1ş borç ekonomik büyüme üzerinde } \\
\text { negatif bir etkiye sahiptir. }\end{array}$ \\
\hline İpek ve Yaşar (2008) & $\begin{array}{l}\text { Türkiye/ 1989- } \\
2007\end{array}$ & $\begin{array}{l}\text { Dış borçlanma ile ekonomik büyüme } \\
\text { arasında kısa ve uzun dönemde iki yönlü } \\
\text { nedensellik ilişkisi vardır. Dış borç ile } \\
\text { ekonomik büyüme arasında uzun dönem } \\
\text { ilişkisi negatif yönlüdür. }\end{array}$ \\
\hline Karagöl (2006) & $\begin{array}{l}\text { Türkiye/ 1960- } \\
2002\end{array}$ & $\begin{array}{l}\text { D1ş borçtaki bir şok ekonomik } \\
\text { büyümeyi pozitif yönde etkilemektedir. }\end{array}$ \\
\hline Javed ve Şahinöz (2005) & $\begin{array}{l}\text { Türkiye/ 1983- } \\
2002\end{array}$ & $\begin{array}{l}\text { Diş borçlar yatırımlar üzerinde negatif, } \\
\text { ihracat üzerinde pozitif etkiye sahiptir. }\end{array}$ \\
\hline Karagöl (2002) & $\begin{array}{l}\text { Türkiye/1956- } \\
1996\end{array}$ & $\begin{array}{l}\text { Borç servisindeki artış ekonomik } \\
\text { büyümeyi negatif yönde etkilemektedir. }\end{array}$ \\
\hline $\begin{array}{l}\text { Ulusoy ve Küçükkale } \\
(1996)\end{array}$ & $\begin{array}{l}\text { Türkiye/ 1950- } \\
1992 \\
\end{array}$ & $\begin{array}{l}\text { Diş borçlanma uzun dönemde ekonomik } \\
\text { büyümeyi olumsuz etkilemektedir. }\end{array}$ \\
\hline
\end{tabular}

Tablo 1: Dış Borç-Ekonomik Büyüme İlişkisine Yönelik Literatür Özeti.

Kaynak: (Çevik ve Cural 2013)' den güncellenmiştir.

\section{Ekonometrik Yöntem}

Regresyon analizi bağımlı ve bağımsız değişkenler arasındaki ortalama ilişkinin matematiksel bir modelle ifade edilmesinde, bağımlı ve bağımsız değişkenin doğrusal bir ilişki içinde olduğunu varsaymaktadır (Tabakan, 
2009). Kısaca, parametrik regresyon analizi öncelikle değişkenlerin arasındaki ilişkinin doğrusal olduğunu varsaymaktadır. Aradaki ilişkinin doğrusal olmadığı durumlarda, bu varsayım geçersiz hale gelmekte ve regresyonu oluşturan parametrelerin güvenilirliği düşerek modelin tahminleme gücü azalmaktadır. Değişkenler arasında herhangi bir fonksiyonel bir ilişki var ise, etkin ve öngörü gücü yüksek modeller oluşturulabilir (Takezawa, 2006). Aksi halde, parametrik regresyon modelleri yerine parametrik olmayan regresyon modelleri kullanılabilir.

Parametrik olmayan regresyon modelleri değişkenler arasındaki ilişkinin türünü fazla dikkate almamakla beraber, regresyon fonksiyonuna odaklanır. Regresyon fonksiyonunun türevlenebilir olması ve sürekli olması modelin tek varsayımı olarak kabul edilebilir (Eubank, 1990). Parametrik olmayan regresyon yöntemi, regresyonu oluşturan parametrelerin katsayıların anlamlılı̆̆ yerine fonksiyonun istatistiksel özellikleri ile ilgilenmektedir (Fox, 2008). Çalışmada ele alınan bağımlı ve bağımsız değişkenler normal dağılım varsayımını sağlamamakta ve kalın kuyruk özellikleri göstermektedir. Bu nedenle parametrik olmayan regresyon çekirdek tahmincisi yardımıyla ilişkiler belirlenmeye çalışılacaktır.

\section{1. Çekirdek Regresyon}

Parametrik olmayan regresyon kestiricileri, parametrik modellerdeki varsayım ihlallerinin yanı sıra dağılım hakkında hiçbir bilgi olmadığı durumlarda kullanılmaktadır. Ayrıca parametrik model kurmaya yardımcı oluşu ve başta çekirdek regresyon olmak üzere diğer tüm kestiricilerinin tutarlı kestirimler sunmasından dolayı parametrik regresyon analizine alternatif olarak tercih edilmektedir (Kıroğlu, 1999). Parametrik olmayan regresyon kestiricilerinin temel amaçları; iki değişken arasındaki ilişkiyi açıklamada çok yönlü bir metot sağlamak, kayıp gözlemleri temsil etmede veya yakın X değerleri arasında bir değer bulmada esnek bir metot kurmak ve aykırı noktaların etkisini inceleyerek sahte gözlemleri ortaya çıkarmaktır (Hardle, 1999).

En basit ve en yaygın kullanılan parametrik olmayan regresyon kestiricileri çekirdek metoduna dayanır (Chu ve Marron, 1991). Çekirdek odaklı kestiriciler basit ve sezgisel olarak iyi anlaşıldı̆̆ 1 için tercih edilmektedir. Diğer önemli parametrik olmayan eğri kestiricileri ise k-en yakın komşuluk, spline modelleri ve ortogonal serilerdir (Hardle, 1999).

Çekirdek regresyonda bağımlı değişkenin yerel ağırlıklı ortalaması alınır. Ağırlıklar çekirdek olarak adlandırılan bir fonksiyona dayanır. Çekirdek adı da buradan gelmektedir (Chu ve Marron, 1991). Çekirdek regresyona ilişkin geliştirilen yaklaşımlar arasında yerel sabit (Nadaraya-Watson), yerel doğrusal ve yerel polinomial çekirdek kestiricileri ile diğer alternatif kestiriciler (Priestley-Chao, Gasser-Müller) yer almaktadır.

Yerel sabit çekirdek kestirim tekniği Nadaraya (1964) ve Watson (1964) tarafindan önerilmiş olup, Nadaraya-Watson çekirdek kestiricisi olarak da adlandırılır. Buradaki mantık, bağımlı değişkenin değerlerini yerel olarak ortalayarak koşullu ortalama fonksiyonunu kestirmektir.

$(X, Y)$ gözlem çiftleri için $f(x, y)$ yoğunluk fonksiyonu kullanılarak elde edilen (Hardle ve Linton, 1994) yerel sabit çekirdek kestiricisi:

$$
\hat{m}(x)=\frac{\sum_{i=1}^{n} Y_{i} K\left(\frac{x-X_{i}}{h}\right)}{\sum_{i=1}^{n} K\left(\frac{x-X_{i}}{h}\right)}
$$

şeklindedir, buradan hareketle; 


$$
\min _{a} \sum_{i=1}^{n}\left(Y_{i}-a\right)^{2} K\left(\frac{x-X_{i}}{h}\right)
$$

ifadesinin minimizasyon problemine odaklıdır (Li ve Racine, 2007). Burada $\mathrm{K}$ çekirdek ya da ağırlık fonksiyonu olup, sıfır etrafında simetriktir ve $\lim _{x \rightarrow \infty}|x| K(x)=0$ özelliğini sağlamaktadır. h, pencere genişliği ya da düzleştirme parametresi adı verilen, kestirim düzegünlüğünü kontrol eden ve genellikle pozitif değer alan parametredir (Schimek, 2000). Bir $\mathrm{X}_{\mathrm{i}}$ gözlem noktasında $h \rightarrow 0$ olduğunda $\hat{m}_{h}\left(X_{i}\right) \rightarrow Y_{i}$ keyfi bir x noktasında ise $h \rightarrow \infty$ olduğunda $\hat{m}_{h}\left(X_{i}\right) \rightarrow \bar{Y}$ olacaktır. Bu iki limit durumundan anlaşılacağı gibi, örnek büyüklüğü $\mathrm{n}$ ile ilişkili olan düzgünleştirme parametresi h, sıfıra ne çok hızlı ne de çok yavaş yakınsamalıdır. (Hardle ve Linton, 1994).

$n \rightarrow \infty$ iken ve $h \rightarrow 0$ ve $n h \rightarrow \infty$ olması şartıyla (1) deki formülde pay ve payda,

$$
\begin{aligned}
& E\left|\sum_{i=1}^{n} Y_{i} K\left(\frac{x-X_{i}}{h}\right)\right| \rightarrow m(x) f(x) \\
& E\left|\sum_{i=1}^{n} K\left(\frac{x-X_{i}}{h}\right)\right| \rightarrow f(x)
\end{aligned}
$$

olacağından $\hat{m}(x) \rightarrow m(x)$ olacaktır (Hardle ve Linton, 1994; He, 2009). Dolayısıyla bu kestirici ile elde edilen regresyon fonksiyonunun, $\mathrm{m}(\mathrm{x})$ 'in tutarlı bir kestirici olduğu söylenebilir (Demir, 2005). Schuster (1972) tarafından gösterildiği gibi,

$$
\begin{aligned}
& \sqrt{n h}\left[\hat{m} h(x)-m(x)-h^{2} \operatorname{Yan}(x)\right] \rightarrow N(0, \operatorname{Var}(x)) \\
& \operatorname{Yan}(x)=\frac{1}{2} u_{2} K\left[m^{\prime \prime}(x)+2 m^{\prime}(x) \frac{f^{\prime}}{f}(x)\right] \\
& \operatorname{Var}(x)=\frac{v_{2}(K) \sigma^{2}(x)}{f(x)}
\end{aligned}
$$

yerel sabit kestirici asimptotik olarak normaldir (Hardle ve Linton, (1994).

\section{2. Çekirdek fonksiyonu ve pencere genişliğinin belirlenmesi}

Her gözlem orta nokta olmak üzere her gözleme yerleştirilen tümseklerin toplamı olarak düşünülen çekirdek kestiricilerinde, hangi yaklaşım kullanılırsa kullanılsın, belirleyici iki etmen bulunmaktadır. Bunlardan biri tümseklerin biçimini ifade eden çekirdek fonksiyonu, diğeri ise tümseklerin yayılımını ifade eden pencere genişliğidir (Toktamış, 1995). Pencere genişliği seçimiyle karşılaştırıldığında çekirdek fonksiyonu seçimi daha az önem arz eden bir husustur. Çekirdek fonksiyonunun şeklindeki değişikliğin kestirime etkisi, pencere 
genişliğindeki değişikliğin neden olacağı etkiden çok daha azdır. Pencere genişliği seçimi ise tüm parametrik olmayan eğri kestiricilerinin uygulamasında ana sorundur (Marron, 1988).

Olasılık fonksiyonu özelliklerini taşıyan herhangi bir fonksiyon olarak alınabilen çekirdek fonksiyonu, en iyi olduğu için değil, kolay uygulanırlığı ve diğer yöntemleri anlamada bir araç olması nedeni ile tercih edilmektedir (Kıroğlu, 1999). Yaygın olarak kullanılan çekirdek fonksiyonları Tablo 2'de sunulmaktadır (Hardle vd., 2004).

\begin{tabular}{|c|c|}
\hline Çekirdek & $\mathrm{K}_{(\mathrm{u})}$ \\
\hline Tekbiçimli & $\frac{1}{2} I(|u| \leq 1)$ \\
\hline Üçgensel & $(1-|u|) I(|u| \leq 1)$ \\
\hline Epanechnikov & $\frac{3}{4}\left(1-u^{2}\right) I(|u| \leq 1)$ \\
\hline İki A ğırlıklı & $\frac{15}{16}\left(1-u^{2}\right)^{2} I(|u| \leq 1)$ \\
\hline Üç Ağırlıklı & $\frac{35}{32}\left(1-u^{2}\right)^{3} I(|u| \leq 1)$ \\
\hline Gaussian & $\frac{1}{\sqrt{2 \pi}} \exp \left(-\frac{1}{2} u^{2}\right)$ \\
\hline Kosinüs & $\frac{\pi}{4} \cos \left(\frac{\pi}{2} u\right) I(|u| \leq 1)$ \\
\hline
\end{tabular}

Tablo 2: Çekirdek Fonksiyonları

K ile gösterilen çekirdek fonksiyonu, Her u değeri için: $K(u) \geq 0, K(u)=K(-u), \int_{-\infty}^{\infty} K(u) d u=1$ ve $\int_{-\infty}^{\infty} K^{2}(u) d u<\infty$ özelliklerine sahiptir (Benedetti, 1997).

Çekirdek kestirimlerinin elde edilmesinde önemli bir etken olan pencere genişliğinin çok küçük seçilmesi, yani çekirdeğin dar olması durumunda her noktadaki ortalama alma süreci daha az sayıda gözleme dayanacağından regresyon fonksiyonunun kestirimi kaba bir kestirim olacaktır. Başka bir deyişle, kestirim sonuçları örnek değişkenliğine fazlaca bağımlı olacaktır (Marron, 1988).

Düzeltme teriminin optimum şekilde belirlenmesi ve parametrik olmayan regresyon fonksiyonunun tahmin gücünün artması; $h$ pencere genişliği seçimine bağlıdır. Literatürde genellikle pencere genişliği seçicileri arasında çapraz geçerlilik ve plug-in yöntemi ile cezalandırma fonksiyonları yer alır. En çok kullanılan Çapraz geçerlilik fonksiyonu, gözlem değerlerinden herhangi birinin seçilmesiyle, diğer (n-1) gözlem değerlerini baz alarak; seçilen noktanın $\left(X_{i}\right)$ pürüzsüzlüğünü tahmin edilmesidir. Bu tahmin; düzgün ve ikinci dereceden türevlendirilebilir bir fonksiyon için kareli artıkları tahmin edilerek, artıkların toplamını minimum yapan düzeltme parametresi olarak tanımlanır (Faraway, 2006). Çapraz geçerlilik fonksiyonu,

$C V(\gamma)=\frac{1}{2} \sum_{J=1}^{n}\left(\gamma_{j}-f_{\gamma(j)}\left(x_{i}\right)\right)^{2}$ şeklinde ifade edilmektedir. 


\section{Veri ve Model Tahmin Sonuçları}

Çalışmada kullanılan ekonometrik modelin amacı Türkiye ekonomisinde dış borç ve ekonomik büyüme ilişkisinin belirlenmesidir. Analiz için Dünya Bankası İstatistiklerinden elde edilen 1970-2013 dönemini kapsayan yıllık veriler kullanılmıştır. Modelde Y: Gayri Safi Milli Hasıla (GSMH) ve X: FD diş borç stoku olarak ele alınmıştır. Çalışmada tahminlerin üretilmesinde $\mathrm{R}$ paket programı ve http://cran.r-project.org/web/packages/np/ internet adresindeki kodlar kullanılmıştır.

Dış borç stokunun GSMH ile ilişkisini belirlemek amacıyla kurulan parametrik regresyon modellerine ait hata terimlerinin normal dağılıma uygunluk göstermediği belirlenmiştir. Ayrıca yaşanan yapısal krizler nedeniyle aykırı (outlier) değerlerin olduğu belirlenmiştir. Aykırı gözlemlerden dolayı parametreler bozulduğu için, varolan güçlü parametrik yöntemlerin uygun çözümler üretemediği ve verinin gerçek yapısı modele yansıtamadığ birçok uygulamacı tarafından ortaya konmuştur. Bu durumda parametrik olmayan regresyon, $\mathrm{X}$ doğrultusunda belirli bir parametrik model olmaksızın ön bilgi sağladığı için uygun olmaktadır.

Çekirdek regresyon yönteminde pencere genişliği çapraz geçerlilik yöntenni ile belirlenmistir. Çapraz geçerlilik yöntemi güçlü (robust) ve asimptotik olarak optimal bir yöntemdir. Buna göre değer 0.08 olarak elde edilmiştir. Çekirdek fonksiyonları Nadaraya- Watson tahmincisine göre elde edilmiştir.

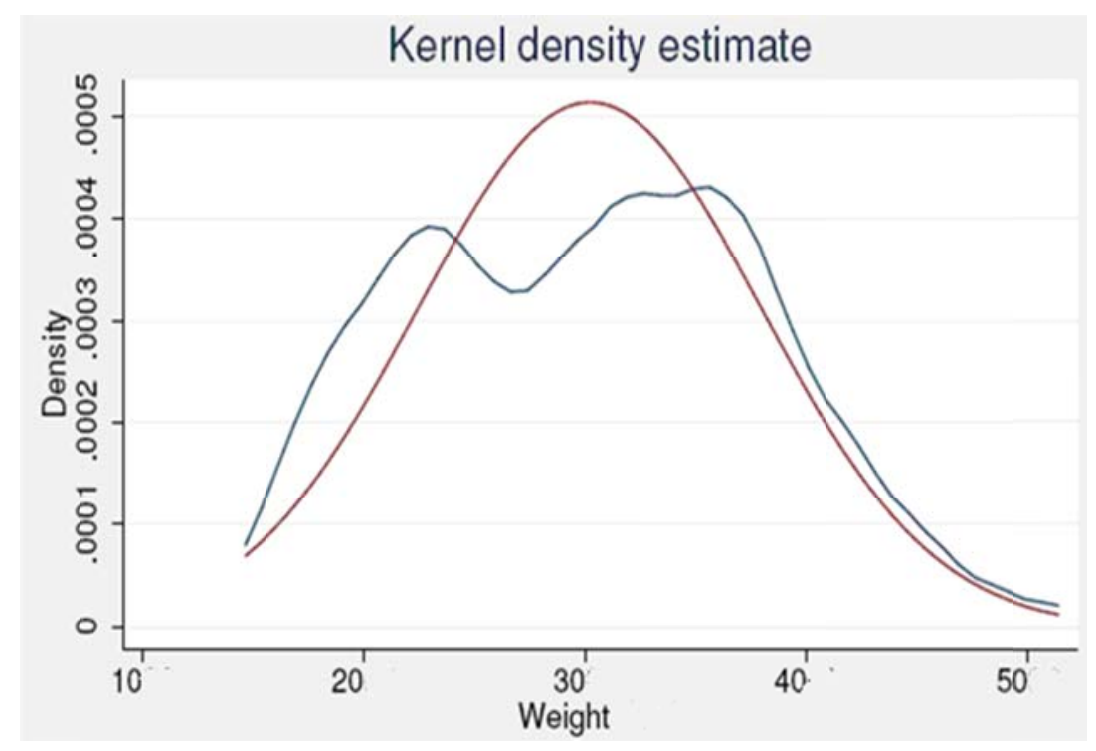

Grafik 1: Çekirdek Yoğunluk Fonksiyonu 


\begin{tabular}{|c|c|c|l|l|l|l|}
\hline $\begin{array}{c}\text { Kullanılan Tahminci } \\
\text { tipi }\end{array}$ & Katsayı & $\mathbf{R}^{\mathbf{2}}$ & $\begin{array}{l}\text { Hata Kareleri } \\
\text { Toplamı }\end{array}$ & Akaike & Schwarz & DW \\
\hline Triangular & $-0.128^{*}$ & 0.42 & 1.238 & -5.763 & -5.127 & 1.88 \\
\hline Uniform & $-0.165^{*}$ & 0.44 & 1.349 & -4.907 & -4.854 & 1.87 \\
\hline Normal & $0.119^{*}$ & 0.41 & 1.552 & -4.794 & -4.835 & 1.88 \\
\hline Biweight & $-0.127^{*}$ & 0.39 & 1.601 & -5.232 & -5.731 & 1.91 \\
\hline Triweight & $-0.108^{*}$ & 0.38 & 1.577 & -5.668 & -5.839 & 1.86 \\
\hline Cosinus & $-0.114^{*}$ & 0.41 & 1.462 & -5.746 & -5.931 & 1.93 \\
\hline Epanechnikov & $\mathbf{- 0 . 1 2 5 *}$ & $\mathbf{0 . 4 6}$ & $\mathbf{1 . 1 1 3}$ & $\mathbf{- 5 . 0 0 3}$ & $\mathbf{- 4 . 5 6 2}$ & $\mathbf{1 . 9 8}$ \\
\hline
\end{tabular}

* 0.05 için istatistik anlamlı parametre

Tablo 3: Nadaraya-Watson Tahmincisi için Çekirdek Regresyon Model Sonuçları

Tahmin sonuçlarından görüleceği üzere her tahminci tipi için elde edilen sonuçlarda FD değişkeninin azaltıcı yönde anlamlı olduğu belirlenmiştir. Hangi tahmincinin sonuçlarının kabul edileceği için akaike ve schwarz kriterinin düşük değer olduğu, $\mathbf{R}^{2}$ değerinin yüksek olduğu ve otokorelasyon probleminin olmadığı alternatif seçilecektir. Buna göre Epanechnikov tercih edilmiştir. Nadaraya-Watson tahmincisi kullanılarak oluşturulan fonksiyonlarının en uygun olanının seçimi için Theil testi, ortalama hata karenin kökü (RMSE), ortalama mutlak hata (MAE) değerleri karşılaştırılmıştır. Bu ölçütlerin değerlerinin sıfıra yaklaşması istenen bir durumdur. Buna göre de en düşük değer olan Epanechnikov uygun olarak belirlenmiştir. Kurulan modellerde Durbin-Watson (DW) katsayısının 2'ye yakın olması genel bir yaklaşım olarak; hata terimleri arasında otokorelasyon bulunmadığ 1 şeklinde yorumlanabilir. FD bağımsız değişkeni bağımlı değişkeni yaklaşık \%12 oranında azaltmaktadır ve bağımlı değişkeni açıklama gücü $\mathbf{R}^{2}=\% 46$ olarak elde edilmiştir. Bulunan sonuç Türkiye ekonomisi için dış borçlarda meydana gelen artışın ekonomik büyümeyi olumsuz etkilediği yönündeki genel literatür ile paralellik göstermektedir. Dış borçlanma ülke ekonomisindeki hassasiyeti arttırmaktadır. (Eser ve Birinci,2014).

\begin{tabular}{|l|l|l|l|l|l|l|c|}
\hline \multicolumn{1}{|c|}{$\begin{array}{c}\text { Kullanılan } \\
\text { Tahminci Tipi }\end{array}$} & Triangular & Uniform & Normal & Biweight & Triweight & Cosinus & Epanechnikov \\
\hline $\begin{array}{l}\text { Ortalama Hata } \\
\text { Karenin kökü }\end{array}$ & 0.0276 & 0.0281 & 0.0263 & 0.0196 & 0.0192 & 0.0257 & $\mathbf{0 . 0 1 0 1}$ \\
$\begin{array}{l}\text { Ortalama } \\
\text { Mutlak Hata }\end{array}$ & 0.0361 & 0.0244 & 0.0370 & 0.0263 & 0.0381 & 0.0362 & $\mathbf{0 . 0 1 7 2}$ \\
$\begin{array}{l}\text { Theil Test } \\
\text { İstatistiği }\end{array}$ & 0.1257 & 0.1871 & 0.2295 & 0.1873 & 0.3086 & 0.2280 & $\mathbf{0 . 1 1 7 3}$ \\
\hline
\end{tabular}

Tablo 4: Nadaraya-Watson Tahmincisi için Regresyon Modelleri İçin Öngörü Kriterleri

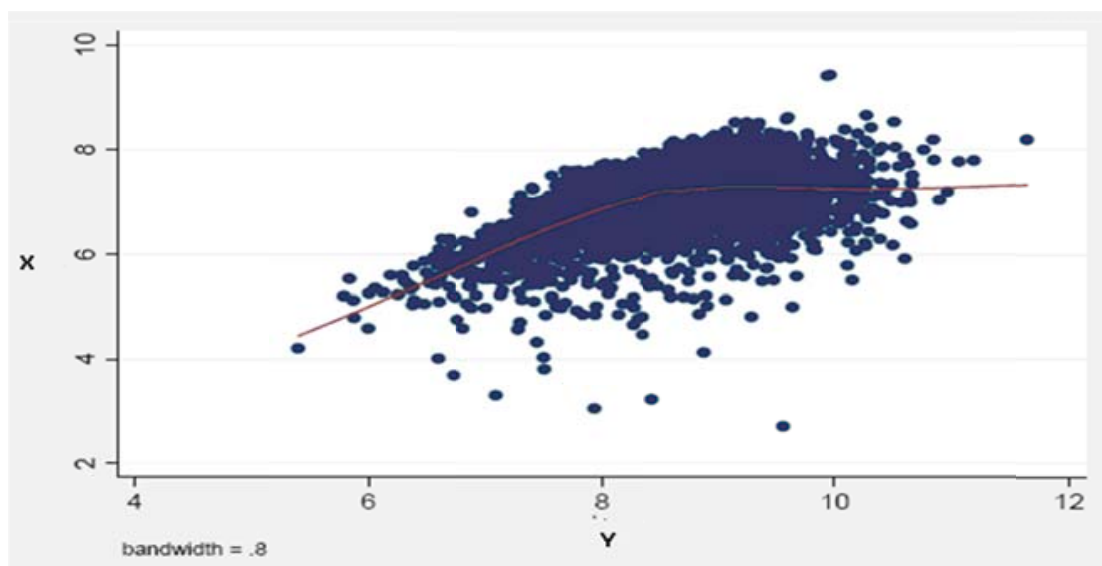

Grafik 2: Nadaraya-Watson Tahmincisi çekirdek fonksiyonu serpilme diyagramı Grafik 2'den görüleceği üzere oluşturulan ağırlık matris değerlerinin birbirine yakınlaşmasına ve belirli bir aralığa kümelenmiş olan verilerin nokta pürüzlülüğü değerlerinin daha uygun bir 
şekilde elde edilmesini sağlamıştır. Tahmincilerin ağırlıklarının kullanılan veri yapısında bir kümelenme gözlenmektedir.

\section{Sonuç}

Teorik olarak dış borçlanmanın verimli yatırım harcamalarında kullanılması, uzun vadeye yayılarak düşük faizli olması ekonomik büyümeyi olumlu etkileyen bir faktör olarak karşımıza çıkmaktadır. Dolayısıyla dış borçlanma, yatırımlar açısından ek bir kaynak sağlamasından dolayı ekonomik büyümeyi olumlu etkilemektedir. Ancak diş borçlanma ile elde edilen kaynaklarla, gelirin gelecekteki borç servisini karşılayacak seviyede arttırılması gereklidir. Dolayısıyla, dış borçlanma ile elde edilen kaynak yabancı borçlanmanın maliyetinden daha fazla getiri ürettikçe, ekonominin yabancı tasarruflar yardımıyla üretim kapasitesi artmaktadır. Ancak yüksek faizli dış borçlanma ile yapılan yatırımların geri ödeme düzeyini sağlayabilecek gelirden daha düşük gelir sağlaması ekonomik büyümeyi olumsuz etkilemektedir. Diş borçlanma ile gelen kaynak başlangıçta ekonomiyi olumlu etkilese de borçların geri ödenmesi ülke dışına önemli kaynak transferine yol açmaktadır. Dış borçlanma ile ülkeye giren ek kaynakların sermaye malı ithalatının oluşturduğu cari işlemler açığının finanse edilmesi durumunda yatırım dolayısıyla da üretimde bir artış yaratması ekonomik büyümeyi olumlu etkileyen bir faktör olarak karşımıza çıkarken, elde edilen ek kaynağın ekonomik büyümeyi yeterli katkı sağlayamaması durumunda dış borçlanmanın ekonomik büyümeyi yavaşlattığg görülmektedir.

Teoride tasarruf eksikliğinin diş borç ile telafi edilmesinin ekonomik büyrümeyi desteklediği görüşü öne çıksa da, uygulamada dış borçların verimli kullanılamaması, borçlanma yoluyla yapılan yatırımların beklenen getiriyi elde edememesi sonucunda dış borçlanmanın ekonomik büyümeyi yavaşlattı̆ğ görüssleri de bulunmaktadır. Dolayısıyla ülkelerin ekonomik durumları, dış borçlanma ile gelen ek kaynakların hangi alanlarda kullanıldığı ve dış borçların ek kaynak üretimindeki etkinliğine göre dış borçlanmanın ülkeler üzerindeki etkisi veya aynı ülkedeki farklı dönemlerdeki etkisi değişiklik göstermektedir.

Türkiye ekonomisi açısından dış borç ekonomik büyüme ilişkisine yönelik literatür taramasına bakıldığında öne çıkan görüşün dış borçlarda meydana gelen artışın ekonomik büyümeyi olumsuz etkilediği yönünde olduğu görülmektedir. Çalışmada Türkiye ekonomisi için 1970-2013 dönemi yıllık verileri ışığında dış borç stoğu ve ekonomik büyüme ilişkisi Çekirdek Regresyon yardımıyla incelenmiştir. Çalışmada çekirdek regresyon yönteminde pencere genişliği çapraz geçerlilik yöntemi ile belirlenmiștir. Çekirdek fonksiyonları Nadaraya- Watson tahmincisine göre elde edilmiştir. Ekonometrik model sonucunda dış borç stokundaki artışın ekonomik büyümeyi \%12 düzeyinde azalttığ 1 bulunurken dış borç stokunun ekonomik büyümeyi açıklama gücünün \%46 seviyesinde olduğu görülmüştür. Elde edilen bulgular 1şığında Türkiye ekonomisi için dış borç stokundaki artış ekonomik büyümeyi olumsuz etkilediği görülmektedir. Bu sonuç Türkiye ekonomisi için genel literatüre paralellik göstermektedir.

Türkiye ekonomisi için dış borç stokundaki artış ile elde edilecek ek kaynağın üretimin artışını daha çok etkileyecek verimli alanlarda kullanılması gerekmektedir. Bu sayede yabancı tasarrufların kullanılması ile yapılacak yatırımlara daha yüksek gelir artışı sağlanmalı, dolayısıyla da elde edilecek üretim artışının borçlanma maliyetinden daha yüksek olması gerekmektedir. 


\section{REFERENCES}

- Abu B. N., Hassan, S. (2008). Empirical Evaluation on ExternalDebt of Malaysia. International Business\&Economics Research Journal, 7(2), 95-108.

- Ajayi, S. I., Khan, M. S. (2000). External Debt and Capital Fliht in Sub-Saharan. International Monetary Fund, Washington D.C.

- Akçay, B. (2012). Borç Krizindeki GIIPS. Ekonomik Yaklaşım Dergisi, Vol. 23, Issue 85, 23-56.

- Benedetti, J. K. (1977). On the Nonparametric Estimation of Regression Functions. Journal of the Royal Statistical Society, 39 (2), 248-253.

- Bilginoğlu, M.A., Aysu, A. (2008). Diş Borçların Ekonomik Büyüme Üzerindeki Etkisi: Türkiye Örneği. Erciyes Üniversitesi. İ̈BF Dergisi Sayı 31, 1-23.

- Chu, C. K., Marron, J. S. (1991). Choosing a Kernel Regression Estimator. Statistical Science, 6 (4), 404-419.

- Claessens, S., Detragiache E., Kanbur R, Wickham P. (1997). Analytical Aspects of the Debt Problems of Heavily Indebted Poor Countries. External Finance for LowIncome Countries. Editors: Zubair Iqbal, Ravi Kanbur, IMF, 21-48.

- Çelik, S., Direkçi, T.B. (2013). Türkiye'de 2001 Krizi Öncesi ve Sonrası Dönemler için Dış Borç Ekonomik Büyüme İlişkisi (1991-2010). Turkish Studies, Volume 8/3, Winter, 111-135.

- Çevik, N.K., Cural M., (2013). İç Borçlanma, Dış Borçlanma ve Ekonomik Büyüme Arasında Nedensellik İlişkisi: 1989-2012 Dönemi Türkiye Örneği. Maliye Dergisi, Sayı 165, Temmuz-Aralık, 115-139.

- Çöğürcü, İ. Çoban, O. (2011). Diş Borç Ekonomik Büyüme İlişkisi: Türkiye Örneği (1980-2009). KMÜ Sosyal ve Ekonomik Araştırmalar Dergisi 13 (21), 133-149.

- Çukurçayır, S. (2014). Türkiye Ekonomisinde Dış Borçların Sürdürülebilirliği: Eşbütünleşme Analizi. Sosyo Ekonomi 2014/2, 8-32.

- Demir, S. (2005). Regresyon Fonksiyonlarının Uyarlanabilir Nadaraya-Watson Çekirdek Kestirimleri. (Doktora Tezi). Ankara: Hacettepe Üniversitesi Fen Bilimleri Enstitüsü.

- Diego, C.R., Stefanoudakis, J. H., Blanco, J.M.T. (2009). External Debt \& Economic Growth. School of Sustainable Development of Societyand Technology, 2009, 1-40.

- Ersoy, H. (2013). Küresel Kriz: Dış Borçlar ve Cari Açık Perspektifinden Türkiye Analizi. Maliye Finans Yazıları, Y11:27, Say1:100, 95-114.

- Erataş, F., Başcı, N. H. (2013). Dış Borç ve Ekonomik Büyüme İlişkisi: "Yükselen Piyasa Ekonomileri" Örneği. Marmara Üniversitesi İİB Dergisi, Cilt XXXV, Sayı II, 207-230.

- Eser, L. Y., Birinci N. (2014). İç ve Dış Borç Tercihlerini Etkileyen Faktörler. Uluslararası Yönetim İktisat ve İşletme Dergisi, Cilt 10, Sayı 23, 31-51.

- Eubank, R. L. (1990). Nonparametric Regression And Spline Smoothing Statistics. A Series Of Textbooks And Monographs, Second Edition.

- Faraway, J. J., (2006). Extending The Linear Model With R. Chapman And Hall /Crc.

- Foot, K. (1989). Buyback, Exit Bondsand the Optimality of Debtand Liquidity Relief. International Economic Review, Vol.30, No.1, 49-70.

- Fox, J. (2008). Applied Regression Analysis And Generalized Linear Models. Sage Publications Inc.

- Hardle, W. (1999). Applied Nonparametric Regression. Cambridge University Press

- Hardle, W, Linton O. (1994). Applied Nonparametric Methods, Cowles Foundation Discussion Paper no: 1069, 1-23. 
- Hardle, W., Müller, M., Sperlich, S., Werwatz, A. (2004). Nonparametric and Semiparametric Models. Springer-Verlag, New York.

- Hayat, M. K., Hayat, M. U. (2010). External Debtand Economic Growt: Empirical Evidence from Pakistan. International research Journal of Finance and Economis, 44, 95-104.

- He, B. (2009). Smoothing Parameter Selection for a New Regression Estimator for Nonnegative Data. (Yüksek Lisans Tezi). Canada: Concordia University.

- Hjertholm, P. (2000). Analytical History of Heavily Indebted Poor Country (HIPC) Debt Sustainability Targets. Discussion Papers 00-03, University of Copenhagen, 145.

- Husain A.M. (1997). Domestic Taxes and the External Debt Laffer Curve. Economica, New Series, Vol. 64, No.255, 519-525.

- Ingham, B. (1995). Economic and Development. McGraw Hill Book Company, London.

- İpek, E., Yaşar, B.K. (2008). Türkiye'de Ekonomik Büyüme ve Dış Borç İlişkisi. Uluslararası Sermaye Hareketleri ve Gelişmekte Olan Piyasalar Uluslararası Sempozyumu, Balıkesir.

- Javed, Z.H. Şahinöz, A. (2005). External Dept: Some Evidence fromTurkish Economy. Journal of Applied Sciences, 5(2), 363-367.

- Karagöl, E. (2006). The Relationship between External Debt, Defence Expenditures and GNP Revisited: The Case of Turkey. Defence and Peace Economics, February, 17(1), 47-57.

- Karagöl, E. (2002). The Causality Analysis of External Debt Sevice and GNP: The Case of Turkey. Central Bank Review (1) 2002, 39-64.

- Kıroğlu, B. G. (1999). Parametrik Olmayan Regresyonda Kestirim Yöntemleri: Kernel Kestirim Yöntemi. İstatistik Araştırma Sempozyumu, DİE, Ankara.

- Krugman, P. (1988 a). Market Based Debt Reduction Schemes. NBER Working Paper Series, Working Paper No 2587, 1-7.

- Krugman, P. (1988 b). Financing vs. Forgiving A Debt Overhang. NBER Working Paper Series, WorkingPaper No. 2486, 1-32.

- Li, O. ve Racine, J. S. (2007). Nonparametric Econometrics: Theory and Practice. Princeton University Press, Princeton

- Marron, J. S. (1988). Automatic Smoothing Parameter Selection: A Survey. Empirical Economics, 13 (3/4), 187-208.

- Nadaraya, E. A., (1964). On Estimating Regression. Theory of Probability and its Applications, 9/1, 186-190.

- Nissanke, M., Ferrarini, B. (2001). Dept Dynamics and Contingency Financing Theoretical Reappraisal of the HIPC Initiative. United Nations University WINDER Dicussion Paper No. 2001/139, 1-46.

- Patenio, J.A.S., Tan-Cruz, A. (2007). Economic Growth and External Debt Servicing of the Philippines: 1981-2005. 10 Th National Convention on Statistics (NCS).

- Pattillo, C., Poirson, H., Ricci, L. (2002). External Debt and Economic Growth. Finance \& Development, 39(2), 1-49.

- Reinhart, M. C., Rogoff, S. K. (2010 a). Growth in a Time of Debt. National Bureau of Economic Research, NBER WorkingPaper No. 15639, 1-26.

- Reinhart, M.C., Rogoff, S. K. (2010 b). The Forgotten History of Domestic Debt. NBER Working Paper Series, 13946, http://www.nber.org/papers/w13946 Erişim Tarihi: 15/01/2015. 
- Safdari, M., Mehrizi, M. A. (2011). External Debt and Economic Groth in Iran. Journal Of Economic and International Finance Vol. 3(5), 322-327.

- Schclarek, A. (2004). Debtand Economic Growth in Developing Industrial Countries. http://www.nek.lu.se/publications/workpap/Papers/WP05_34.pdf Erişim Tarihi: $15 / 01 / 2015$.

- Schimek, M. G. (2000). Smoothing and Regression. A Wiley-Interscience Publication, Canada.

- Schuster, E. F. (1972). Joint Asymptotic Distribution of the Estimated Regression Function at a Finite Number of Distinct Points. Annals of Mathematical Statistics, 43 (1), 84-88.

- Susam, N., Bakkal, U. (2008). Kriz Süreci Makro Değişkenleri ve 2009 Bütçe Büyüklüklerini Nasıl Etkileyecek?. Maliye Dergisi, Sayı 155, 72-88.

- Tabakan, G. (2009). Yarı Parametrik Regresyonda Tahmin Metodları. Çukurova Üniversitesi, Fen Bilimleri Enstitüsü, İstatistik Bölümü, İstatistik Anabilim Dalı Doktora Tezi, Http://Tez2.Yok.Gov.Tr/, Erişim 16/10/2012.

- Takezawa, K. (2006). Introduction To Nonparametric Regression. Wiley Series In Probability And Statistics, John Wiley And Sons Inc.

- Toktamış, Ö. (1995). Olasılık Yoğunluk Fonksiyonunun Çekirdek Kestirimi Üzerine Bir Çalışma. Hacettepe Fen ve Mühendislik Bilimleri Dergisi, 16, 145-163.

- Ulusoy, A., Küçükkale, Y. (1996). Türkiye'de Dış Borçlanmanın İktisadi Büyüme ve Enflasyon üzerine Etkisi: Granger Nedensellik Testi. Ekonomik Yaklaşım, Cilt 7, Sayı 21, 13-25.

- Uysal, D., Özer, H, Mucuk, M. (2009). Dıș Borçlanma ve Ekonomik Büyüme İlişkisi: Türkiye Örneği (1965-2007). Atatürk Üniversitesi İ̈BF Dergisi Cilt 23, Say1 4, 161178.

- Ülgen, Gülden. (2002). Türkiye'de Dış Borcun Sürdürülebilirliği. Marmara Üniversitesi İIBF Dergisi Cilt XX sayı 1, 19-34.

- Watson, G. S. (1964). Smooth Regression Analysis, Sankhya, Series A, 26, 359-372. 